\title{
Effect of boric acid on antioxidant enzyme activity, lipid peroxidation, and ultrastructure of midgut and fat body of Galleria mellonella
}

\author{
Ender Büyükgüzel • Kemal Büyükgüzel • \\ Milena Snela • Meltem Erdem • \\ Katarzyna Radtke • Kazimierz Ziemnicki • \\ Zbigniew Adamski
}

Received: 31 October 2012 / Accepted: 14 February 2013 /Published online: 9 March 2013

(C) The Author(s) 2013. This article is published with open access at Springerlink.com

\begin{abstract}
Boric acid is widely used as an insecticide, acaricide, herbicide, and fungicide and also during various industrial processings. Hence, numerous populations are subjects to this toxic compound. Its action on animals is still not fully known and understood. We examined the effect of boric acid on larvae of greater wax moth (Galleria mellonella). The chemical appeared to be toxic for larvae, usually in a concentration-dependent manner. Exposed groups revealed increased lipid peroxidation and altered activity of catalase, superoxide dismutase, glutathione $S$-transferase, and glutathione peroxidase. We also observed changes of ultrastructure, which were in tune with biochemical assays. We suggest that boric acid has a
\end{abstract}

E. Büyükgüzel · K. Büyükgüzel · M. Erdem

Department of Biology, Faculty of Arts and Science,

Karaelmas University,

67100 Zonguldak, Turkey

M. Snela $\cdot$ K. Radtke $\cdot$ Z. Adamski

Electron and Confocal Microscope Laboratory,

Faculty of Biology, Adam Mickiewicz University,

U1, Umultowska 89,

61-614 Poznan, Poland

K. Ziemnicki $\cdot$ Z. Adamski $(\bowtie)$

Department of Animal Physiology and Developmental Biology, Faculty of Biology, Adam Mickiewicz University, Poznań, Poland

e-mail: ed@amu.edu.pl broad mode of action, which may affect exposed larvae, and even if sublethal, they may lead to disturbances within exposed populations.

Keywords Antioxidantenzymes · Boric acid - Galleria mellonella $\cdot$ Lipid peroxidation $\cdot$ Oxidative stress $\cdot$ Ultrastructure
Abbreviations
BA Boric acid
ER Endoplasmic reticulum
CAT Catalase
GST Glutathione $S$-transferase
GPx Glutathione peroxidase
$\mathrm{LC}_{\mathrm{x}} \quad$ Concentration lethal to $x$ percent of a population
LOEC Least observable effect concentration
MDA Malondialdehyde
ROS Reactive oxygen species
SOD Superoxide dismutase

\section{Introduction}

Boric acid (BA) occurs naturally in both sea and fresh waters at concentrations $1-5 \mathrm{ppm}$. It is also present in the earth crust, in various concentrations, from several dozens up to more, c.a. $300 \mathrm{mg}$ of boron per kilogram 
of soil (Eckel and Langley 1988). Borates are the naturally occurring form of boron, and they are degraded no further (ATSDR 2010). BA is soluble in water and therefore leachable through soil. The persistence in soil depends from its $\mathrm{pH}$ and minerals present in soil (for detailed information, see USDA report 2006). BA alters biological functions of various animals, including insects. Therefore, it is often used as a pesticide. It belongs to the oldest insecticides used in agriculture. It can be used against various insects, like cockroaches, ants, termites, fleas, and other insects. BA is also used for in-hive trapping in natural beekeeping (Handbook for Natural Beekeeping), since it is regarded as one of the least-toxic pesticides and as essentially non-toxic to honey bees (Atkins 1987; Harper et al. 2012). It acts as an absorber of insect cuticle wax and stomach poison of still unclear mode of action. Besides, BA is a component of various nonpesticidal mixtures; it is an important raw material of wood preservatives, a fire retardant, and for manufacturing glass, light bulbs, porcelain enamel, or ceramic glazes. It can be released into the environment during coal burning and power generation. It is used as a drug to treat fungal infections, too (Harper et al. 2012). The global market of BA is still expanding. Therefore, the probability of being exposed to this substance is increasing.

The data on the effect of boron compounds on terrestrial invertebrate species is limited (compare USDA report 2006). Because of that, there is a need of further studies of BA toxic action on various species. Various xenobiotics stimulate production of reactive oxygen species (ROS) (Freeman and Crapo 1982; Harris 1992; Adamski et al. 2003; Krishnan and Sehnal 2006; Hyršl et al. 2007). BA unbalances antioxidant-pro-oxidant equilibrium (Hyršl et al. 2007) and leads to oxidative damage in some tissues, increasing insects' mortality. In consequence, BA may cause toxic results at various levels of biological organization. Such effects may result either from pro-oxidant activity of some xenobiotics, which can be observed as protein/lipid peroxidation or altered antioxidant enzyme activity. Therefore, the values of these parameters (peroxidation and enzymatic activity) are important in estimation of the stress caused by xenobiotics.

The increased activity of enzymes may protect exposed species against ROS. Our previous studies showed that greater wax moth (Galleria mellonella) is sensitive to BA and oxidative stress (Hyršl et al. 2007). Therefore, we decided to examine if BA can alter lipid peroxidation, measured as malondialdehyde (MDA) concentration, as well as the activity of the following antioxidant enzymes: superoxide dismutase (SOD), catalase (CAT), glutathione $S$-transferase (GST), and glutathione peroxidase (GPx), in chosen tissues of this species. The moth can be found in Europe, Asia, North America, and Australia. Larvae destroy beehives, and therefore, they are regarded as pests. Its development is described in detail. The laboratory culture is easy to maintain. The knowledge of the effect of BA on terrestrial invertebrates is scanty. We lack knowledge of its mechanisms of action, insects' defense mechanisms, as well as we do not have endpoints, which could be used as bioindicators of stress. Therefore, the species seems to be a good object of ecotoxicological and toxicological studies. We focused on two larval organs: the midgut and fat body. The midgut is important as an organ where ingested xenobiotics may enter the insect's body. The fat body plays a very important role in detoxification and also in endocrinology, reproduction, and nourishment of insects. Therefore, any disturbance within these two organs may lead to important sublethal changes of the insect's physiology and behavior.

To obtain a more complete explanation of toxic action of this insecticide, we decided to compare the abovementioned measurements with the ones done with the use of transmission electron microscopy. We focused especially on alterations within nuclei, mitochondria, and endoplasmic reticulum (ER) in tested tissues as possible bioindicators of stress. Additionally, in fat body cells, we focused on lipid droplets. These changes are frequently met when tissues are exposed to xenobiotics (Adamski et al. 2005, Adamski 2007; da Silva et al. 2010).

The aim of this study was to examine whether exposure to BA correlates with insects' mortality, and chosen biochemical and ultrastructural parameters.

\section{Materials and methods}

Insects

Larvae of the greater wax moth, G. mellonella (L.), were used in all experiments. The insects were reared in 1,000-ml glass jars with an artificial diet (Bronskill 1961), at $30 \pm 1{ }^{\circ} \mathrm{C}$ in constant darkness. The standard 
diet was composed of $420 \mathrm{~g}$ of bran, $150 \mathrm{ml}$ of filtered honey, $150 \mathrm{ml}$ of glycerol, $20 \mathrm{~g}$ of ground old dark honeycomb, and $30 \mathrm{ml}$ of distilled water. Fifteen newly emerged adult females were placed in jars and provided a piece of old honeycomb on the diet for egg deposition and feeding of newly hatched larvae. The methods used to prepare and dispense diets into container, and the methods used to obtain eggs and larvae and their placement onto diets were described in previous studies (Hyršl et al. 2008; Büyükgüzel et al. 2010).

\section{Experimental designs}

BA (crystal form, $99 \%, \mathrm{H}_{3} \mathrm{BO}_{3}$, Eti Mine Works General Management, Ankara, Turkey) was directly incorporated into diets at concentrations of 156, 620, 1,250 , and 2,500 $\mathrm{ppm}$. Using standard laboratory rearing conditions, two series of experiments were carried out to examine the effects of BA on the insect. In the first one, the lethal effects of various concentrations of BA were determined. These data were used for probit analysis of the lethal activity of BA to G. mellonella larvae. The parameters were lipid peroxidation levels, protein profiles, and activities of antioxidant enzymes in hemolymph and fat body of last instar larvae (VIIth). These stages were used in the biochemical analyses. For electron microscopic studies, the same, last instar, but not prepupal larvae were used. The time of exposure depends on the concentration-BA slowed down larval development - and varied from 22 (control and $156 \mathrm{ppm}$ ) to 25 days (higher concentrations of BA).

Five groups of larvae ( 80 individuals each, four subgroups of 20 insects per concentration) were exposed to BA in the following concentrations: control, 156, 620, 1,250, and 2,500 ppm. After exposure, percentages of dead larvae were calculated, and mortality curve, correlation coefficient, and some chosen $\mathrm{LC}_{\mathrm{x}}$ values $\left(\mathrm{LC}_{1}, \mathrm{LC}_{5}, \mathrm{LC}_{10}, \mathrm{LC}_{30}, \mathrm{LC}_{50}\right.$, and $\mathrm{LC}_{95}$ ) were determined using probit analysis (Finney 1971):

Probit of mortality $=\log \mathrm{A}+\mathrm{B} \times \log ($ concentration $)$.

The lowest of the values $\left(\mathrm{LC}_{1}\right)$ is close to least observable effect concentration (LOEC) value (the lowest concentration that causes toxic effects).
Together with the next three values $\left(\mathrm{LC}_{5}, \mathrm{LC}_{10}\right.$, and $\mathrm{LC}_{30}$ ), they show if environmental exposure to low or moderate concentrations may be a threat to the exposed population, whereas the two highest ones $\left(\mathrm{LC}_{50}\right.$ and $\mathrm{LC}_{95}$ ) are standard values presented when toxicity of substances is estimated.

The two lower of the used concentrations (156 and $620 \mathrm{ppm})$ and the next groups of 80 larvae were exposed to them.

\section{Biochemical assays}

First instar larvae were reared through VIIth instars on artificial diets amended with given concentrations of BA (156 and $620 \mathrm{ppm}$ ). The larvae were transferred into another jar lined with a filter paper for pupation. Last instar larvae were used for determining protein content, MDA content as indicator of lipid peroxidation, and antioxidant enzyme activities. The larvae were chilled on ice for $5 \mathrm{~min}$ and surface sterilized in $95 \%$ ethanol. Fat body and midgut were dissected from larvae into a chilled Eppendorf tube charged with cold homogenization buffer $\left(w / v 1.15 \% \mathrm{KCL}, 25 \mathrm{mM} \mathrm{K}_{2} \mathrm{HPO}_{4}\right.$, $5 \mathrm{mM}$ ethylenediaminetetraacetic acid EDTA, $2 \mathrm{mM}$ phenylmethylsulfonyl fluoride PMSF, $2 \mathrm{mM}$ dithiothreitol DDT, pH7.0). For protein analysis, $5 \mathrm{mg}$ of both tissues were homogenized in a diluted sample buffer using ultrasonic homogenizer (Elma, Singen, Germany) for $8 \mathrm{~min}$. A few crystals of phenylthiourea (PTU) were added to each sample to prevent melanization. The samples for biochemical assays were frozen at $-25{ }^{\circ} \mathrm{C}$ until use.

Sample preparation and determination of malondialdehyde (MDA) content and antioxidant enzyme activities

Extracts of midgut and fat body were prepared at $4{ }^{\circ} \mathrm{C}$ by an ultrasonic homogenizer (Bandelin Sonopuls, HD2070, Berlin, Germany) at 50 W, 40-50 s in homogenization buffer, and subsequent centrifugation at $10,000 \times g$ for $10 \mathrm{~min}$. The resulting cell-free extracts were collected for biochemical analysis. MDA contents and antioxidant enzyme activities were determined by measuring the absorbance of the samples in a dual beam spectrophotometer (Shimadzu 1700, UV/VIS Spectrophotometer, Kyoto, Japan). Assays were replicated four times each with five larvae. Protein concentrations were 
determined according to Lowry et al. (1951) by using bovine serum albumin (BSA) as a standard. All chemicals used were analytical grade and were obtained from Sigma-Aldrich (St. Louis, MO, USA).

MDA content was assayed according to Jain and Levine (1995). MDA reacts with thiobarbituric acid (TBA) to form a colored complex. MDA contents as an indicator of lipid peroxidation were determined after incubation at $95{ }^{\circ} \mathrm{C}$ with TBA $(1 \% w / v)$. Absorbances were measured at $532 \mathrm{~nm}$ to determine MDA content. MDA content were expressed as nanomoles per milligram protein by using $1.56 \times 10^{5} \mathrm{M}^{-1} \mathrm{~cm}^{-1}$ for extinction coefficient.

Total SOD (EC 1.15.1.1) activity was determined according to Marklund and Marklund (1974) assaying the auto-oxidation and illumination of pyrogallol at $440 \mathrm{~nm}$ for $3 \mathrm{~min}$. One unit total SOD activity was calculated as the amount of protein causing $50 \%$ inhibition of pyrogallol auto-oxidation. The total SOD activity was expressed as units per milligram of protein.

CAT (EC1.11.1.6) activity was measured according to Aebi (1984) assaying the hydrolyzation of $\mathrm{H}_{2} \mathrm{O}_{2}$ and decreasing absorbance at $240 \mathrm{~nm}$ over $3 \mathrm{~min}$ at $25{ }^{\circ} \mathrm{C}$. CAT activity was expressed as millimoles of $\mathrm{H}_{2} \mathrm{O}_{2}$ reduced per minute per milligram of protein, using $\epsilon_{240}=0.0394 \mathrm{mM}^{-1} \mathrm{~cm}^{-1}$.

GST (EC 2.5.1.18) activity was assayed by measuring the formation of the GSH and 1-chloro-2,4-dinitrobenzene (CDNB) conjugate (Habig et al. 1974). The increase in absorbance was recorded at $340 \mathrm{~nm}$ for $3 \mathrm{~min}$. The specific activity of GST was expressed as nanomoles GSH-CDNB conjugate formed per minute per milligram protein using an extinction coefficient of $9.6 \mathrm{mM}^{-1} \mathrm{~cm}^{-1}$.

GPx (EC1.11.1.9) activity was measured with $\mathrm{H}_{2} \mathrm{O}_{2}$ as substrate according to Paglia and Valentine (1987). This reaction was monitored indirectly as the oxidation rate of NADPH at $340 \mathrm{~nm}$ for $3 \mathrm{~min}$. Enzyme activity was expressed as nanomoles of NADPH consumed per minute per milligram of protein, using an extinction coefficient of $6220 \mathrm{M}^{-1} \mathrm{~cm}^{-1}$.
All assays were corrected for nonenzymatic reactions using corresponding substrate in phosphate buffer (50 mM, pH7.0).

\section{Ultrastructural research}

Larvae were anesthetized, dissected, and the fat body and midgut were isolated and were fixed with $2 \%$ glutaraldehyde in $0.175 \mathrm{M}$ cacodylate buffer, postfixed with $1 \% \mathrm{OsO}_{4}$, dehydrated, and finally embedded in Spurr's resin. Ultrathin sections $(70 \mathrm{~nm})$ were obtained using a Leica ultramicrotome, stained with uranyl acetate and lead citrate, and observed under the JEOL 1200EX II JEM Transmission Electron Microscope.

Statistical analysis

Data on the activities of antioxidant enzymes and MDA content were evaluated by analysis of variance (ANOVA). To determine significant differences between means, least significant difference (LSD) test (SPSS 1997) was used. When the $F$ estimate exceeded the probability of 0.05 , the differences were considered significant.

\section{Results}

Probit analysis

All tested concentrations of BA caused significant, concentration-dependent mortality of G. mellonella larvae (Table 1). The logarithmic dependence between BA concentration and the probit of mortality is expressed as the following equation:

$Y=+2.5285+1.12095$ (log concentration)

There is a high correlation between BA concentration and number of dead individuals found within the
Table 1 Mortality of Galleria mellonella larvae exposed to four concentrations of BA

\begin{tabular}{llll}
\hline BA concentration (ppm) & No. of exposed larvae & No. of dead larvae & Mortality (\%) \\
\hline Control (0.0) & 80 & 4 & 5.0 \\
156 & 80 & 44 & 55.0 \\
620 & 80 & 52 & 65.0 \\
1,250 & 80 & 73 & 91.1 \\
2,500 & 80 & 72 & 90.0 \\
\hline
\end{tabular}


Table 2 Values of lethal concentrations obtained after exposure of Galleria mellonella to boric acid

\begin{tabular}{ll}
\hline Lethal concentration & $\begin{array}{l}\text { Concentration of boric acid }[\mathrm{ppm}] \\
(95 \% \text { confidence interval })\end{array}$ \\
\hline $\mathrm{LC}_{50}$ & $160(55.717-268.29)$ \\
$\mathrm{LC}_{95}$ & $4,704.2(2,246.8-9,849.4)$ \\
$\mathrm{LC}_{1}$ & $1.346(0.195-9.303)$ \\
$\mathrm{LC}_{5}$ & $5.459(1.218-24.472)$ \\
$\mathrm{LC}_{10}$ & $11.518(3.229-41.083)$ \\
$\mathrm{LC}_{30}$ & $54.618(24.359-122.46)$ \\
\hline
\end{tabular}

tested groups $(r=0.90)$. The slope of dependence line is high $(B=1.12) . \mathrm{LC}_{50}$ equals $160 \mathrm{ppm}$ (Table 2$)$.

Probit analysis indicates that the 156-ppm concentration can be potentially highly harmful (c.a. $50 \%$ of mortality); $620 \mathrm{ppm}$ responds to about $\mathrm{LC}_{72-73}$. They are located at the steep, middle part of the curve. Mortality for the two highest concentrations is located at the upper plateau of the sigmoid concentrationmortality curve. Both the first and the last part of the sigmoid curve are plane. That affects the preciseness of data reading. Therefore, we decided to focus on the first two concentrations during the next experiments.

\section{Biochemical parameters}

In most of the cases, exposure to BA resulted in a concentration-dependent increase of the measured parameter. We observed statistically significant increase of lipid peroxidation, expressed as MDA content within the fat body and the midgut ( $t$ test, $p<0.05$ ). Although measured values of MDA were comparable among tissues, peroxidation of fat body increased c.a. twice as high, as peroxidation of midgut, when compared to control values (Fig. 1). Measured values of MDA in the fat body were 3- and 4.5-fold higher than control one, for 156 and $620 \mathrm{ppm}$, respectively, whereas they were 1.5 and 2.4 times higher for values measured in the midgut. In the fat body, the difference between all groups was statistically significant. In the midgut, only the higher concentration resulted in statistically significant increase of MDA content.

The activity of total SOD was higher in the fat body than in the midgut (Fig. 2). In both cases, it showed concentration-dependent increase of activity in response to exposure to BA. Again, effect on the fat body was much higher than on the midgut, with values about six times higher in the fat body than in the midgut exposed to the same concentration of BA. In case of both tissues, only 620 ppm BA caused statistically significant increase of SOD activity.

CAT activity decreased in the fat body exposed to BA (Fig. 3a). On the contrary, its activity increased in the midgut, and for $620 \mathrm{ppm}$, BA reached values more than three times higher than in control (Fig. 3b). In both cases, we saw proportional dependence.

GST activity had the same trend as SOD - its activity increased in the fat body and in the midgut (Fig. 4). The increase was concentration dependent in both tested tissues. All the groups showed statistically significant altered values of GST activity. The increase was higher in the midgut than in the fat body when compared to control. However, control activity of this enzyme was much higher in the fat body than in control.

The activity of GPx showed different mode of changes in case of both tested tissues (Fig. 5). Whereas the fat body showed prominent, statistically
Fig. 1 Malondialdehyde content in control and boric acid-exposed fat body and midgut tissues. Concentrations of boric acid: 156 and 620 ppm. Bars represent means + standard deviations (SD) of replicates. Means followed by the same letter (not underlined for the fat body and underlined for the midgut) are not significantly different

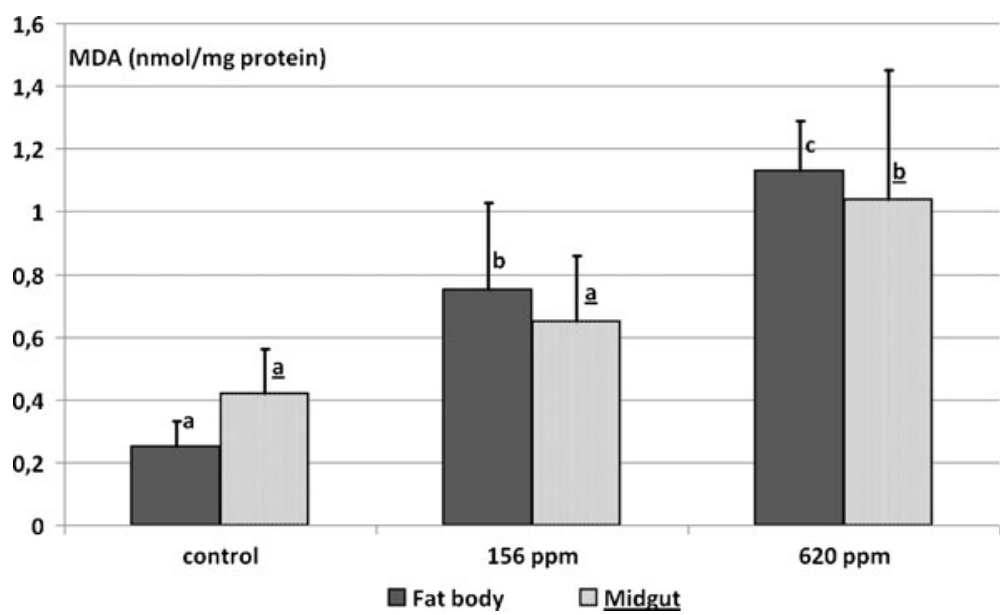


Fig. 2 Superoxide

dismutase activity in control and boric acid-exposed fat body and midgut tissues.

Concentrations of boric acid: 156 and 620 ppm. Bars represent means + standard deviations (SD) of replicates. Means followed by the same letter (not underlined for the fat body and underlined for the midgut) are not significantly different

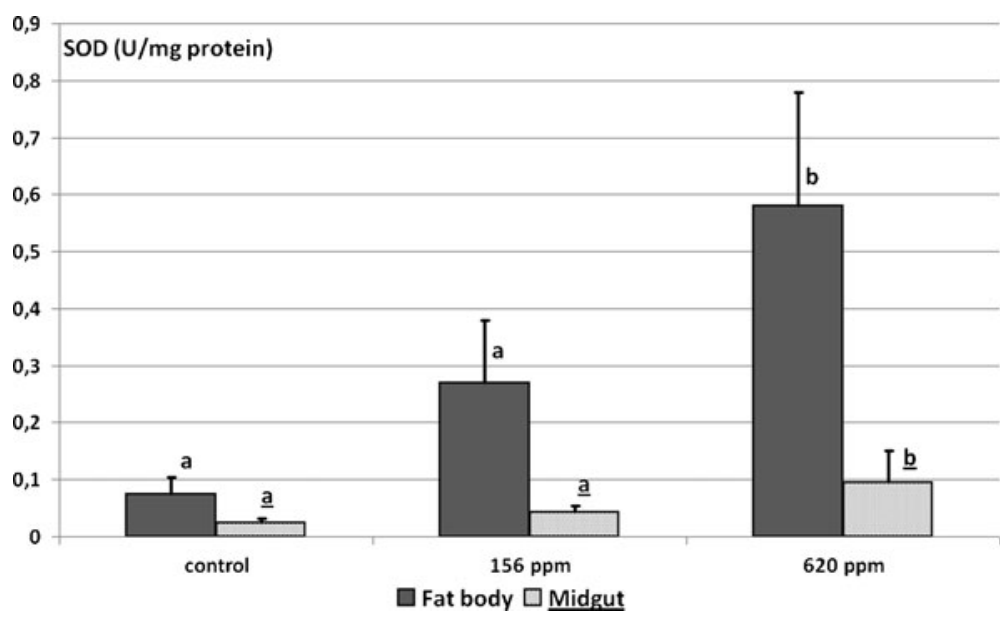

significant increase of activity in 156 ppm BA group, with no statistically significant difference among
620 ppm BA and control groups, the midgut showed adverse effect: insignificant change in 156 ppm BA
Fig. 3 Catalase activity in control and boric acidexposed fat body (a) and midgut (b). Concentrations of boric acid: 156 and 620 ppm. Bars represent means + standard deviations (SD) of replicates. Means followed by the same letter (not underlined for the fat body and underlined for the midgut) are not significantly different
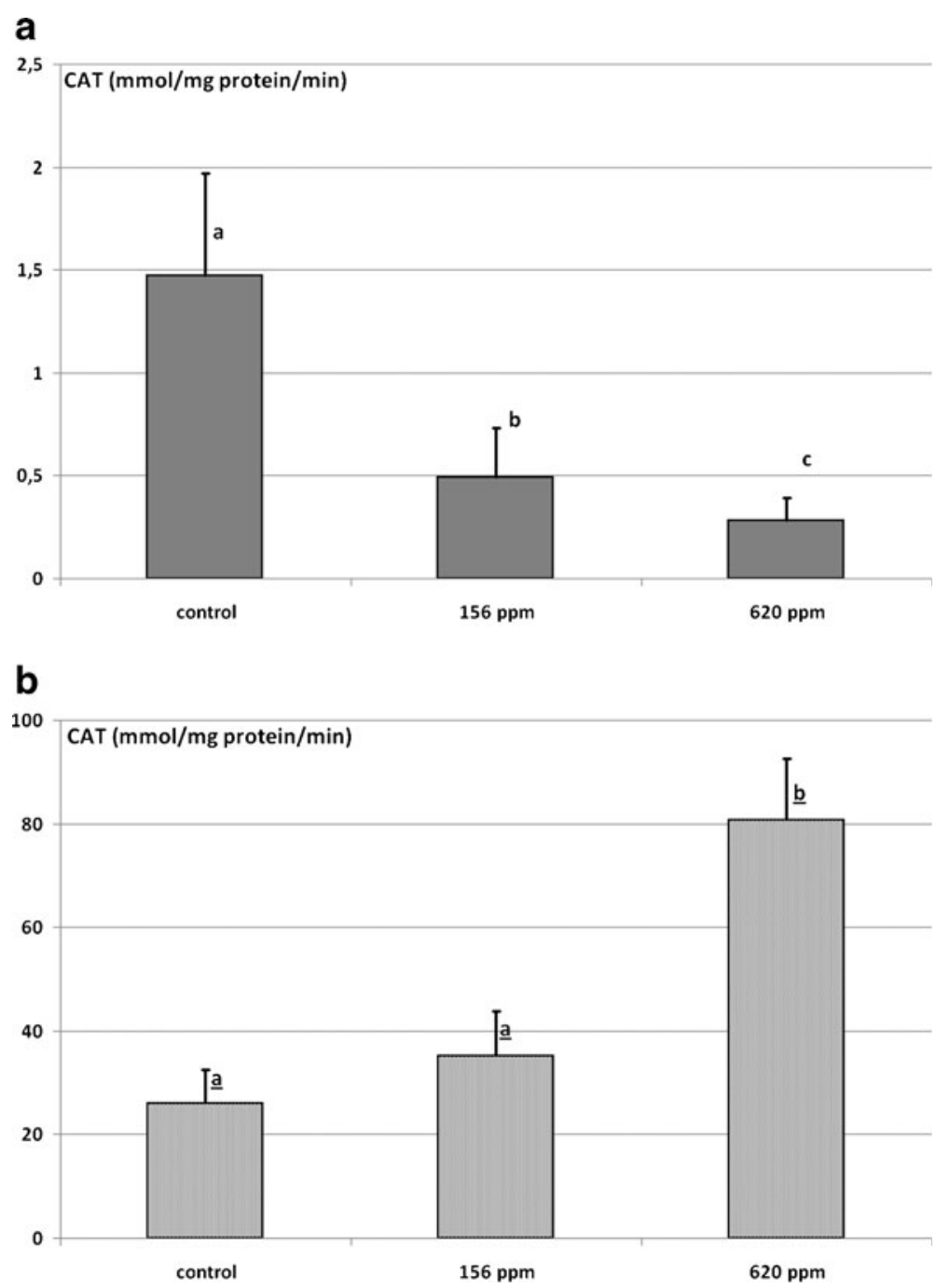
Fig. 4 Glutathione $S$-transferase activity in control and boric acid-exposed fat body and midgut. Concentrations of boric acid: 156 and $620 \mathrm{ppm}$. Bars represent means + standard deviations (SD) of replicates. Means followed by the same letter (not underlined for the fat body and underlined for the midgut) are not significantly different

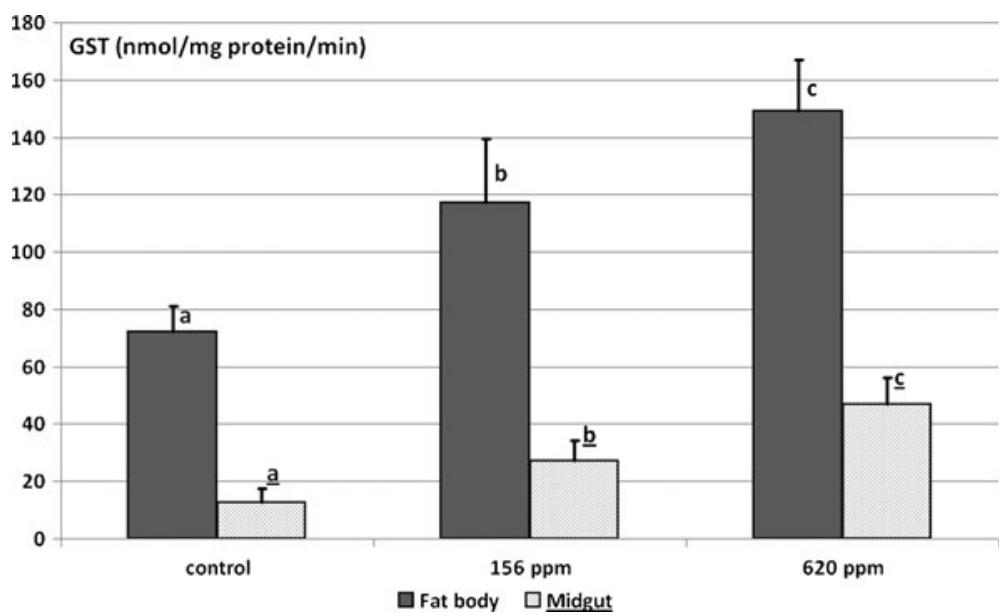

group and high statistically significant increase of GPx activity in 620 ppm BA group.

Effect of BA on fat body ultrastructure

Control fat body consisted of cells which posses numerous fat body granules, with regular shape and homogenous structure. Mitochondria and ER grouped around the nuclei. The nuclei had an oval shape and many patches of heterochromatin (relatively high ratio; Fig. 6a). Mitochondria were electron dense (they absorb most energy from an electron beam, which refers to density of the structure, Fig. 6b).

On the contrary, fat body of insects exposed to $156 \mathrm{ppm}$ showed heterogenic fat droplets, which fused together (Fig. 7a). We observed large intercellular spaces; cells lost connection between each other (Fig. 7b-d). Beginnings of vacuolization within cytoplasm (Fig. 7c, d), mitochondrial vacuolization
(Fig. 7d), as well as pyknotic nuclei (Fig. 7c) could be noticed. Similar changes, but of a higher intensity, were observed within the group exposed to higher concentration of BA (Fig. 8a-d). Lipid droplets were more intensively heterogeneous: there was an electron-lucent rim and electron-dense core. Again, droplet fusion (Fig 8a) and vacuolization of mitochondria (Fig. 8d) were observed. Myelinated figures were present within the cytoplasm (Fig. 8a, b).

\section{Effect of BA on midgut ultrastructure}

Control TEM pictures of midgut revealed cells that possessed nuclei with low heterochromatin ratio and regular oval shape. Nuclei were surrounded by a rim of cytoplasm where numerous as well as electron-lucent mitochondria were located (Fig. 9a, b). Mild malformations of midgut ultrastructure were observed in samples exposed to $156 \mathrm{ppm}$ BA. Cytoplasmic vacuolization was observed
Fig. 5 Glutathione peroxidase activity in control and boric acid-exposed fat body and midgut. Concentrations of boric acid: 156 and 620 ppm. Bars represent means + standard deviations (SD) of replicates. Means followed by the same letter (not underlined for the fat body and underlined for the midgut) are not significantly different

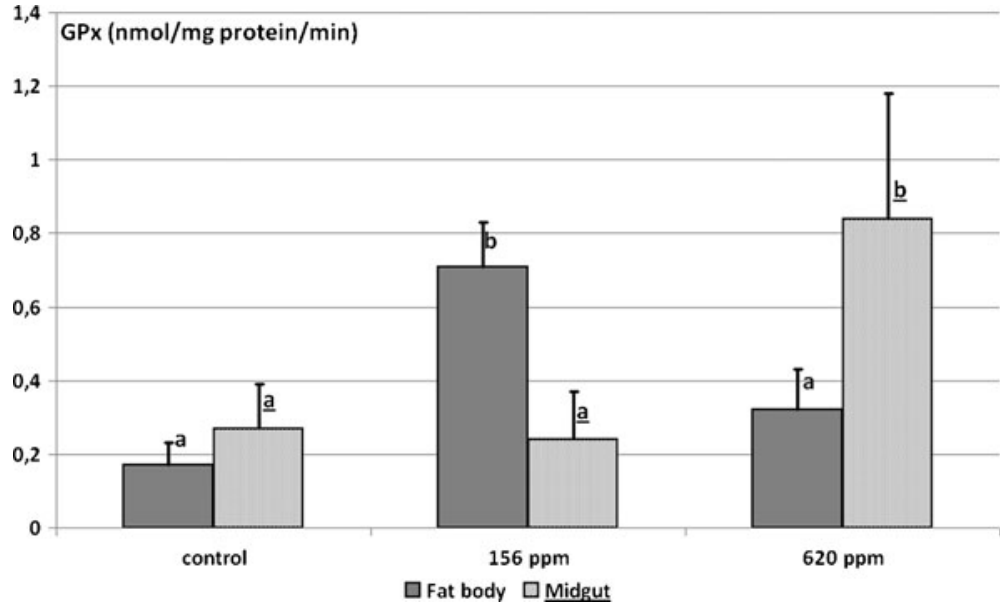


Fig. 6 Control fat body cells. Note regular shape of nucleus $(N)$, its envelope $(N E ; \mathbf{a})$, and separated fat body droplets $(F ; \mathbf{a}, \mathbf{b})$. Mitochondria $(M)$ are intact (b). Cells adhere to each other (white arrow)
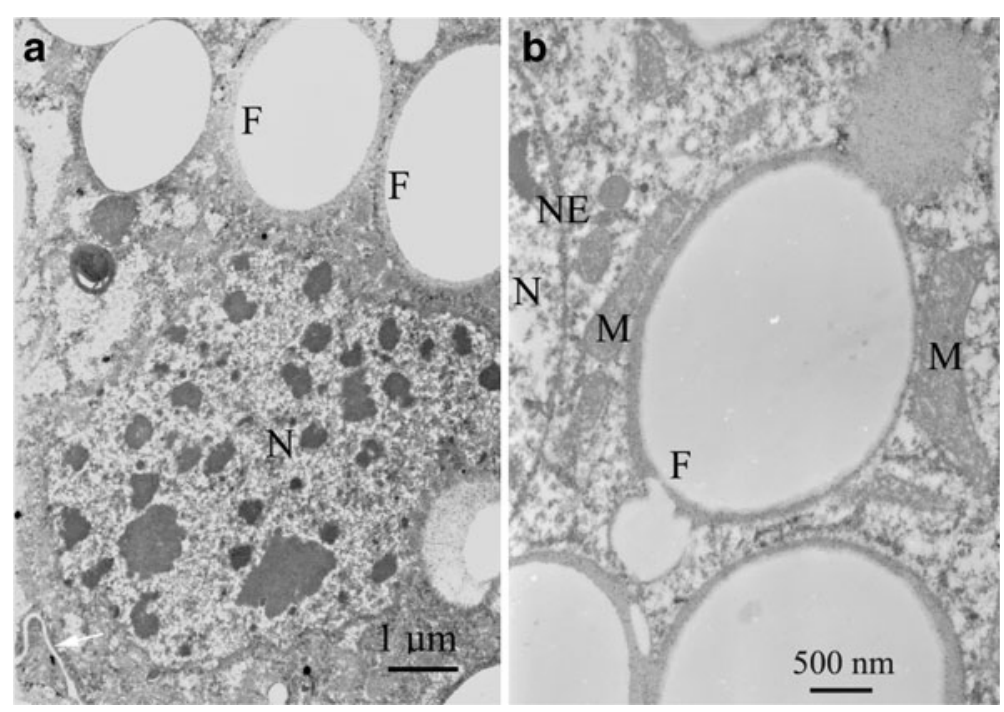

Fig. 7 Fat body cells, 156 ppm of BA. Cells lose connections to each other (b-d, white arrows). Fat droplets $(F)$ are not homogenous (a-c, asterisks), and they start to fuse $(\mathbf{a}-\mathbf{c}$, black arrowheads). Minor vacuolization of mitochondria $(M)$ begins $(\mathbf{b}, \mathbf{d}$, white arrowheads). Pyknotic nucleus is also visible (c, black arrow)
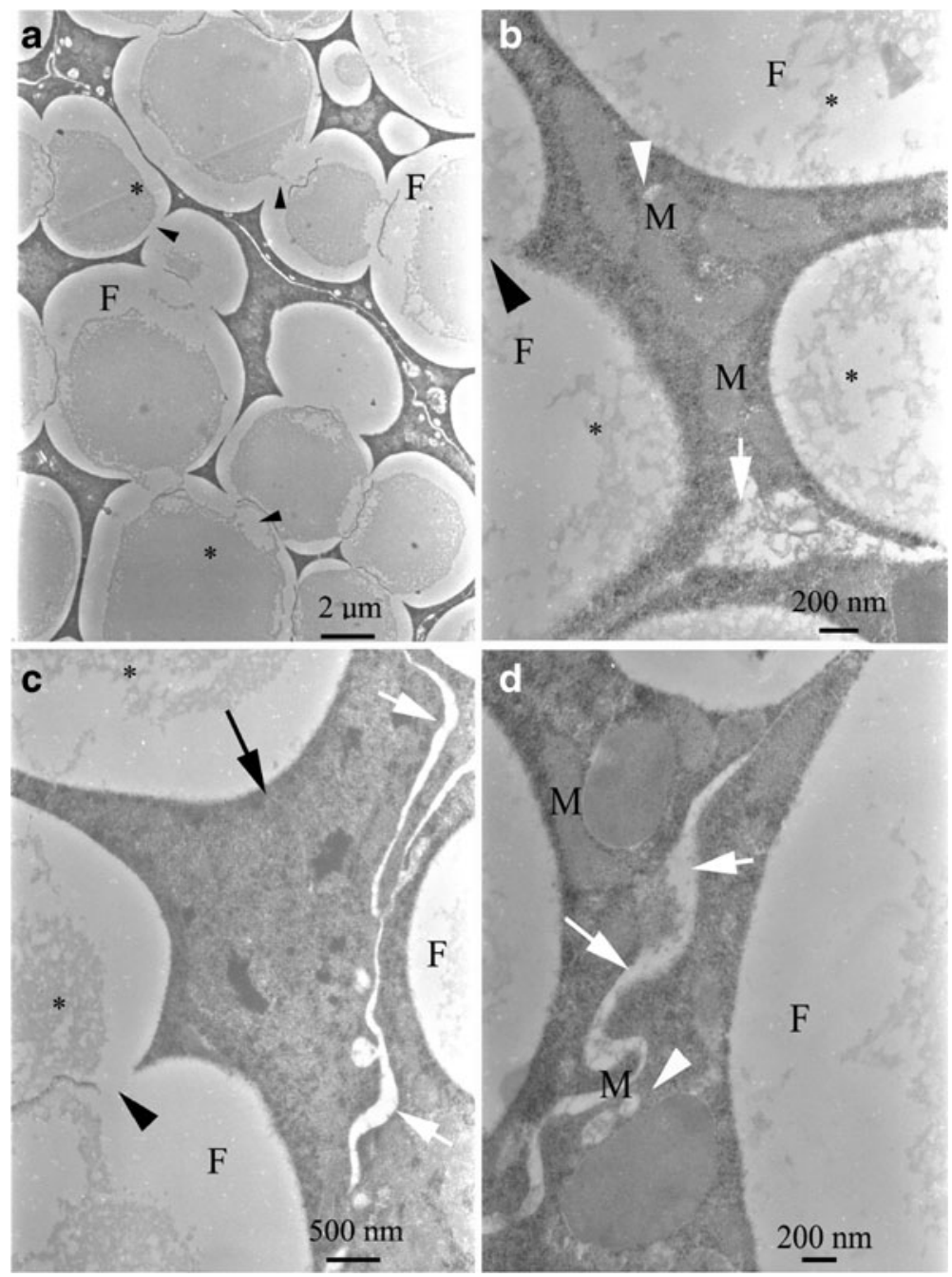
Fig. 8 Fat body cells, $620 \mathrm{ppm}$ of BA. Note wide space between cells (b, c, white arrows). Not homogenous (a-c, asterisks) and fusing fat droplets $(F ; \mathbf{a}, \mathbf{c}$, black arrowheads).

Advanced vacuolization of arrowheads). Myelinated figures (a, b, caret symbol) and pyknosis (a, black arrow). Vacuolization of cytoplasm (b-d). Nuclei $(N)$ show invaginations $(\mathbf{a}-\mathbf{c})$, but nuclear envelope $(N E)$ is not swollen mitochondria $(M ; \mathbf{d}$, white
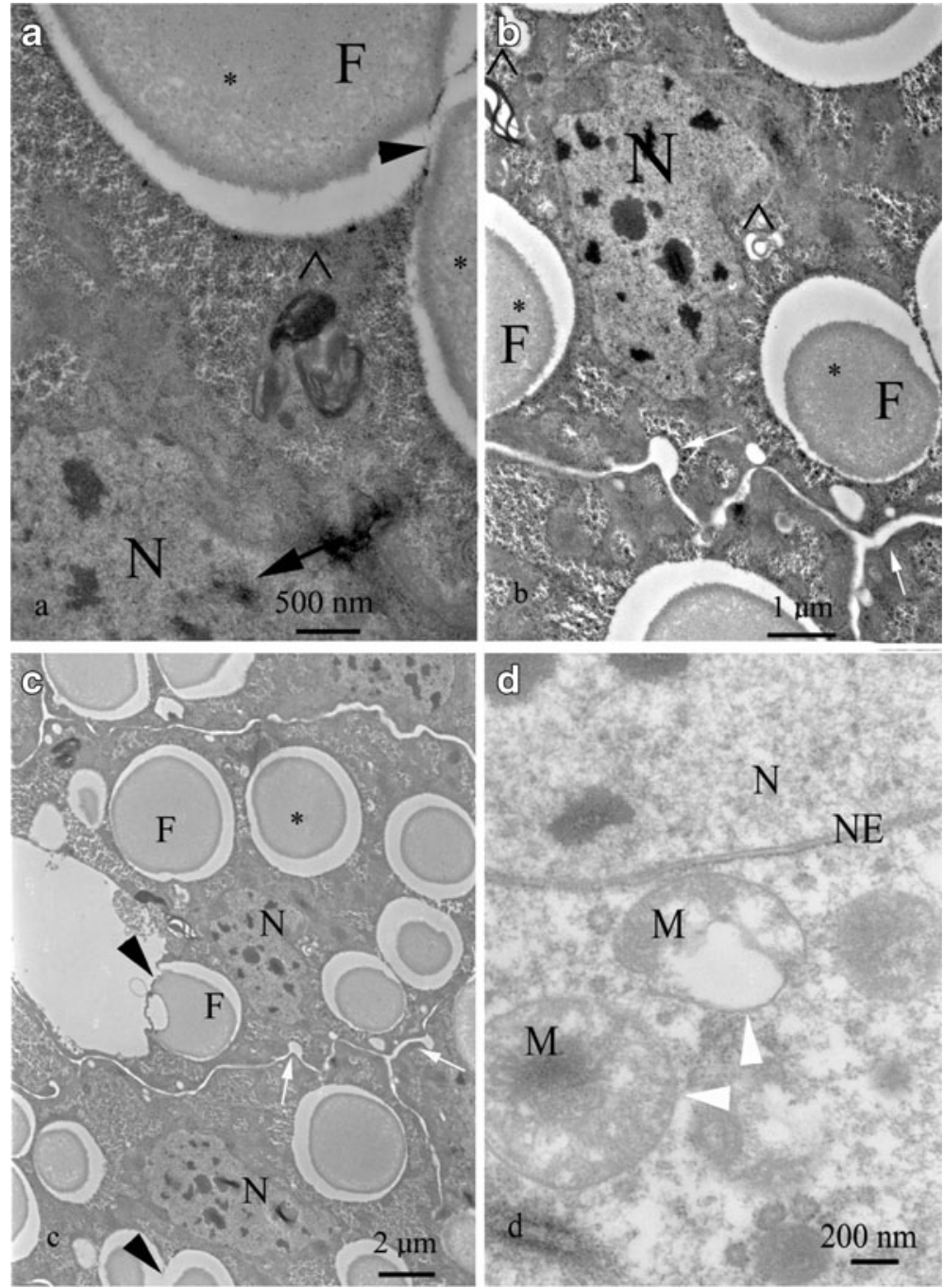

Fig. 9 Midgut control. Note oval regular shape of nuclei $[N$; including nuclear envelope $(N E)]$. Numerous not malformed mitochondria $(M)$ and endoplasmic reticulum $(E R)$
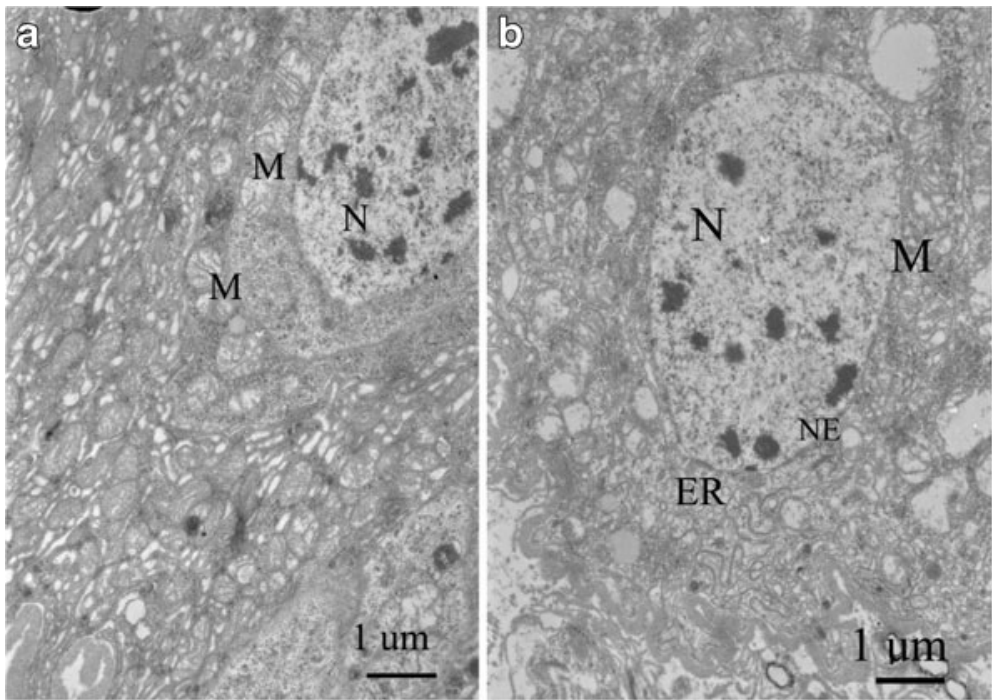
Fig. 10 Midgut 156 ppm. a Apical part of midgut cells. b Basal part. No changes of nuclei $(N)$ were noticed.

Mitochondria $(M)$ and endoplasmic reticulum were intact, too. Weak vacuolization of electron lucent cytoplasm is visible (a, b, asterisks)
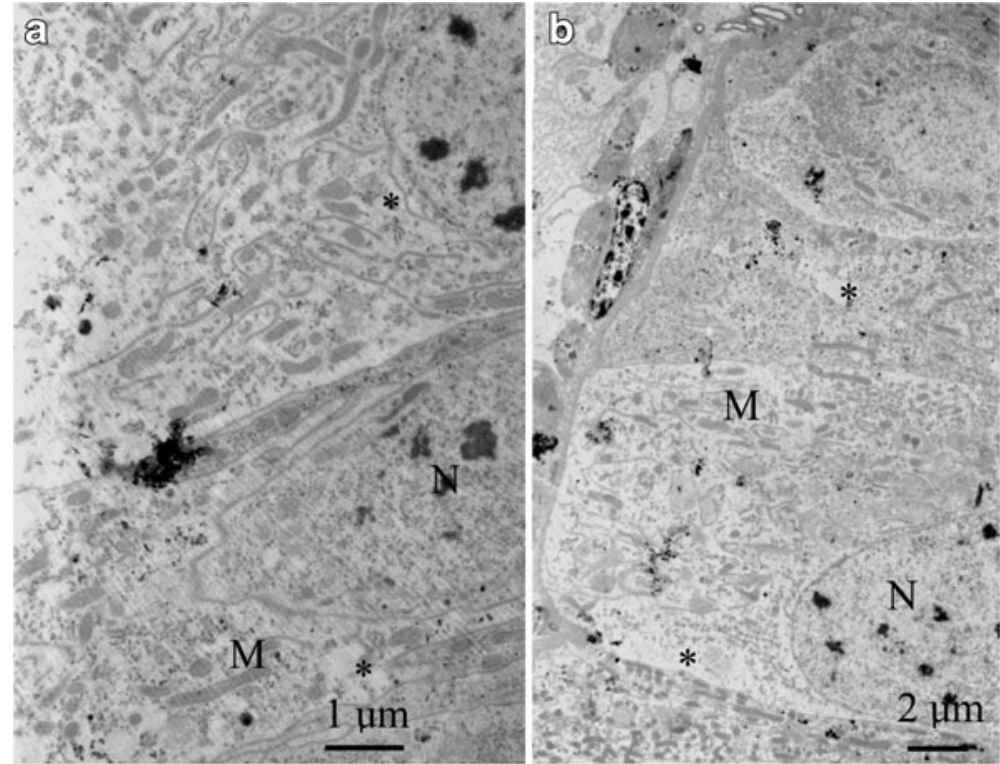

(Fig. 10a); mitochondria were electron dense (Fig. 10b). Nuclei, however, did not show irregularities within their membrane (Fig. 10a), and the pattern of heterochromatin was similar to the controls. The higher concentration caused some more prominent changes, like rupture of cell membrane, vacuolization of the cytoplasm, and
Fig. 11 Midgut 620 ppm. Nuclei $(N)$ are not harmed. Some malformation at the brush border. Rupture of cell membrane can be noticed (a, b, black arrows). Swollen endoplasmic reticulum $(E R ; \mathbf{c}, \mathbf{d}$, black arrowheads). Vacuolization of cytoplasm appears (b, c, asterisks). Within regenerative crypt, one of the cells shows pyknotic figures (e, white arrow) and more electron-dense cytoplasm
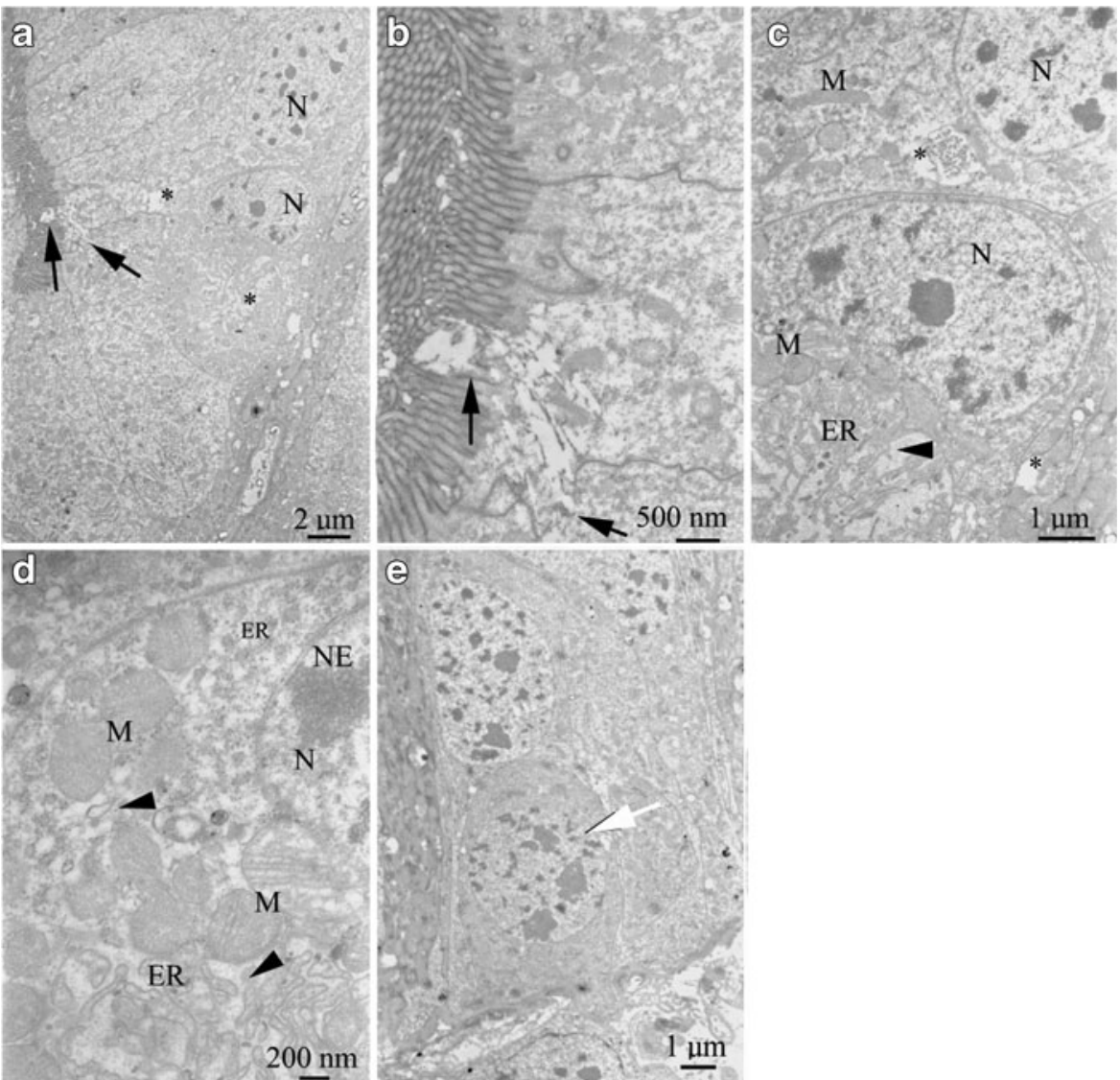
swelling of ER in the apical part of the cell (Fig. 11a, b). ER was swollen also in the basal part of the cells, close to the nuclei (Fig. 11c, d). Mitochondria, located close to intact nuclei, were similar to those from the control. Nuclei of columnar epithelium were not malformed. However, we observed some pyknotic nuclei within regenerative crypts (Fig. 11e).

\section{Discussion}

BA is a frequently used pesticide. Various non-target species are exposed to it. In this research, we showed that BA may be potentially harmful to insects. Lethal and sublethal effects were observed in G. mellonella exposed to a wide range of concentrations. The values causing high mortality are low, BA can be used in concentration as low as $1 \%$ (Xue et al. 2011), i.e., much higher than we used. $\mathrm{LC}_{50}$ for bees is more than two times higher than obtained for G. mellonella (EPA 1996). The two lowest concentrations (156 and $620 \mathrm{ppm})$ respond to the steep part of the sigmoid concentration-mortality curve. They enable us to observe sublethal and subacute toxicity of BA and are not far from concentrations used to eradicate pests. Death is the easiest endpoint; it rarely gives enough information concerning the toxic activity of any substance. Sublethal endpoints, however, bring a lot of data. Therefore, we decided to study closer the two lowest tested concentrations. One hundred fifty-six parts per million respond to about $49-50 \%$ of mortality within exposed population. Six hundred twenty parts per million respond to calculated $\mathrm{LC}_{72}-\mathrm{LC}_{73}$. Already at the upper plateau of the concentrationmortality curve are 1,250 and 2,500 ppm. High slope indicates that the concentration lethal for a higher percentage of the population can be easily obtained. One must remember that values causing 10-20\% mortality within the population are a serious threat for them in the environment. The calculated value for $\mathrm{LC}_{10}$ is c.a. $11 \mathrm{ppm}$, while the values responding LOEC ( $\mathrm{LC}_{1}$ in this case) can be as small as $1 \mathrm{ppm}$. Therefore, BA can cause significant disturbances within exposed populations.

The changes we observed are in tune with the ones reported previously (Hyršl et al. 2007). There are no significant difference between results obtained for the fat body in that research and the ones reported here. Both the values and the tendencies described in both papers are similar, and they indicate that BA causes oxidative stress. One can notice that results observed for hemolymph and fat body are not always concurrent. Tissues and organs differ in their response to the stress, their abilities to detoxify xenobiotics, as well as the time of the exposure. Therefore, the various responses of the fat body and the midgut are not surprising. Some of the observed ultrastructural changes are typical for the increased level of ROS, too. We noticed similar connection between presence of ROS and ultrastructural changes in case of some pesticides (compare Adamski et al. 2003, 2005; Adamski 2007). Therefore, we can assume that induction of ROS present during exposure to various xenobiotics and effects in ultrastructural changes. In consequence, it leads to decreased vivacity of exposed animals.

Peroxidation was a few times higher in the BA exposed fat body and the BA exposed midgut than within control. Increased MDA content may indicate that the defense mechanisms of given cells and tissues are not satisfactory. Increased activity of majority of tested antioxidant enzymes suggests that they play important role against BA toxicity and that BA causes oxidative stress is tissues. Activity of the majority of enzymes in both tissues increased. Nevertheless, it did not protect the tissues from peroxidation. This suggests that defense mechanisms of exposed insects were broken. That was supported by harmed membranes and fat droplet observed under TEM. Next, oxidative stress led to ultrastructural alterations within lipid membranes and fat droplets. In consequence, we could observe fused membranes, malformed mitochondria, and nuclei.

Of the four tested enzymes, SOD showed the highest increase of activity. For the fat body and the midgut, SOD activity at $620 \mathrm{ppm}$ was 7.7 and 3.9 times higher than in control, respectively. This suggests that this enzyme or, rather, two enzymes, mitochondrial SOD and cytoplasmic SOD, play a crucial role in defense against ROS during toxic action of BA. Interestingly, BA decreased CAT activity within fat body. It may be assumed that CAT and SOD cooperate, and they change their activities in a coordinated mode. However, the inversed relationship which we report for fat body is not a unique phenomenon. Such relationship was found also by Felton and Summers (1995). Also, Qiang et al. (2012) found uneven changes of CAT and SOD in response to stress (cold temperature). Low activity of CAT might be compensated by increased GPx activity. It increased significantly in 
response to both tested concentrations. This is in tune with research of Habes et al. (2001) who reported increase of GST activity in response to various concentrations of BA. Activity of antioxidant enzymes might differ among various organs exposed to BA and borax (Ince et al. 2010).

Electron microscopic observations revealed various alterations within cells exposed to BA of concentrations around the $\mathrm{LC}_{50}$ level. Many of them resemble changes observed after exposure of insects to other xenobiotics, which also cause oxidative stress (Adamski et al. 2005; Adamski 2007). Therefore, we suggest that described changes could be caused by elevated ROS levels that surpass the capacity of the antioxidant defense system. Within the fat body, ultrastructural changes referred to altered fat droplets, loss of connections between cells, changes of nuclei, and vacuolization of both cytoplasm and mitochondria. Some of those changes, but of a lower intensity, were observed within the midgut: vacuolization of cytoplasm, mild mitochondrial, and nuclear irregularities. These changes indicate that BA causes complex changes within exposed individuals and affects various organs, tissues, and cells. The low intensity of midgut malformation may be due to the relatively short time of exposure to this substance. Perhaps BA is transported quickly to hemolymph and fat body. Therefore, it does not harm the cells very much. The only exception is the apical part of the columnar cells. This part of the cell is in direct constant contact with unabsorbed food within lumen of a midgut. In consequence, they are in prolonged contact with BA. On the contrary, fat body cells revealed much more prominent alterations. Fat body plays an important role in detoxification; therefore, plenty of BA and its metabolites are probably transferred here. The interesting and important point is the noticed malformation of regenerative cells. Stem cells, by definition, do not possess elaborated ER or other organelles, which may play an important role in detoxification. Therefore, they are at higher risk than the other gut cells. In consequence, replacement of cells in gut may be disturbed, and even though the gut is not seriously destroyed by a direct BA action or ROS activity, it may show impairment of its functioning. Exposure to BA resulted in changes in the ultrastructure of nuclei within fat body, as well as some midgut cells, too. In consequence, cellular metabolism must be altered.
There is limited data concerning ultrastructure of tissues affected by BA. Habes et al. (2001) described thickening of midgut and its destruction after exposure to $8.2 \%$ BA. However, the authors show light microscopic observations. Therefore, it is hard to refer to their results. Perhaps increased midgut size was due to vacuolization of cells. Similar ultrastructural changes were observed by Sumida et al. (2010) in ants and da Silva et al. (2010) in bees exposed to BA. Midgut cells were vacuolized, membranes were ruptured, and myelinated figures were observed, too. However, due to higher BA concentrations used by these authors, the changes were of much higher intensity and could even lead to pyknosis and to death of cells. On the other hand, we could observe some pyknotic nuclei, too. Loss of connection between cells, changes of lipid droplets, and vacuolization of cytoplasm might surely affect other physiological processes, including hormonal regulation of development - some of the important insects' hormones are produced on the basis of lipids.

All these changes suggest that BA has a broad action on exposed insects, even in very low concentrations. Moreover, due to changes in vital tissues, these changes may affect other organs and processes, which are not directly exposed to BA and its metabolites.

Acknowledgments The authors thank four anonymous reviewers for their critical reading, valuable remarks, and helpful suggestions. We also thank Bülent Ecevit University, Zonguldak, Turkey and Adam Mickiewicz University, Poznań, Poland, for their support in this collaborative research.

Open Access This article is distributed under the terms of the Creative Commons Attribution License which permits any use, distribution, and reproduction in any medium, provided the original author(s) and the source are credited.

\section{References}

Adamski Z. Exposure to carbaryl leads to ultrastructural changes and alters activity of antioxidant enzymes in Spodoptera exigua (Lepidoptera: Noctuidae). Invertebr Biol. 2007;126:191-201.

Adamski Z, Ziemnicki K, Fila K, Žikič R, Štajn A. Effects of long-term exposure to fenitrothion on Spodoptera exigua and Tenebrio molitor larval development and antioxidant enzyme activity. Biol Lett. 2003;40:43-52.

Adamski Z, Banaszkiewicz M, Ziemnicki K. Ultrastructural and developmental alterations in larvae of Tenebrio molitor $\mathrm{L}$. (Insecta, Coleoptera) induced by sublethal concentrations of fenitrothion. J Biol Res. 2005;3:15-22.

Aebi H. Catalase in vitro. Methods Enzymol. 1984;105:121-6. 
Atkins EL. Laboratory Bee Adult Toxicity Tests (BATDT) for boric acid, powdered, 100\% technical. MRID 40269201. 1987.

ATSDR, 2010. Toxicological profile for boron. U.S. Department of Health and Human Services. Public Health Service. Agency for Toxic Substances and Disease Registry. 2010. http://www.atsdr.cdc.gov/ToxProfiles/tp.asp?id=453\&tid=80

Bronskill J. A cage to simplify the rearing of the greater wax moth, Galleria mellonella (Pyralidae). J Lep Soc. 1961;15:102-4.

Büyükgüzel E, Hyrsl P, Büyükgüzel K. Eicosanoids mediate hemolymph oxidative and antioxidative response in larvae of Galleria mellonella L. Comp Biochem Physiol A Mol Integr Physiol. 2010;156:176-83.

da Silva CA, da Silva-Zacarin EC, Bueno OC, Malaspina O. Morphological alterations induced by boric acid and fipronil in the midgut of worker honeybee (Apis mellifera L.) larvae: morphological alterations in the midgut of $A$. mellifera. Cell Biol Toxicol. 2010;26:165-76.

Eckel WP, Langley WD. A background-based ranking technique for assessment of elemental enrichment in soils at hazardous waste sites. 9th National Superfund '88 Conference. Washington, DC. 1988; 282-286.

EPA Reregistration Eligibility Document: Boric acid and its sodium salts. 1996. U.S. Environmental Protection Agency, Office of Prevention, Pesticides, and Toxic Substances, Office of Pesticide Programs, U.S. Government Printing Office: Washington, DC.

Felton GW, Summers CB. Antioxidant systems in insects. Arch Insect Biochem Physiol. 1995;29:187-97.

Finney DJ. Probit analysis. New York: Cambridge University Press; 1971.

Freeman BA, Crapo JD. Biology of disease: free radicals and tissue injury. Lab Invest. 1982;47:412-26.

Habes D, Kilani-Morakchi S, Aribi N, Farine JP, Soltani N. Toxicity of boric acid to Blattella germanica (Dictyoptera: Blattellidae) and analysis of residues in several organs. Meded Rijksuniv Gent Fak Landbouwkd Toegep Biol Wet. 2001;66:525-34.

Habig WH, Pabst MJ, Jakoby WB. Glutathione-S-trans-ferases: the first enzymatic step in mercapturic acid formation. $\mathrm{J}$ Biol Chem. 1974;249:7130-9.

Harris ED. Regulation of antioxidant enzymes. FASEB J. 1992;6:2675-83.

Harper B, Gervais JA, Buhl K, Stone D. Boric Acid Technical Fact Sheet; National Pesticide Information Center, Oregon
State University Extension Services. 2012. http:// npic.orst.edu/factsheets/borictech.pdf.

Hyršl P, Büyükgüzel E, Büyükgüzel K. The effects of boric acid-induced oxidative stress on antioxidant enzymes and survivorship in Galleria mellonella. Arch Insect Biochem Physiol. 2007;66:23-31.

Hyršl P, Büyükgüzel E, Büyükgüzel K. Boric acid-induced effects on protein profiles of Galleria mellonella hemolymph and fat body. Acta Biol Hung. 2008;59:281-8.

Ince S, Kucukkurt I, Ibrahim Hakki Cigerci IH, Fidan AF, Eryavuz A. The effects of dietary boric acid and borax supplementation on lipid peroxidation, antioxidant activity, and DNA damage in rats. J Trace Elem Exp Med. 2010;24:161-4.

Jain SK, Levine SN. Elevated lipid peroxidation and vitamin Equinone levels in heart ventricles of streptozotocin-treated diabetic rats. Free Radical Biol Med. 1995;18:337-41.

Krishnan N, Sehnal F. Compartmentalization of oxidative stress and antioxidant defense in the larval gut of Spodoptera littoralis. Arch Insect Biochem Physiol. 2006;63:1-10.

Lowry OH, Rosebrough NI, Farr AL, Randall RJ. Protein measurement with the Folin phenol reagent. J Biol. Chem. 1951;193:265-275

Marklund S, Marklund G. Involvement of the super-oxide anion radical in the autoxidation of pyrogallol and a convenient assay for superoxide dismutase. Eur J Bio-chem. 1974;47:469-74.

Paglia DE, Valentine WN. Studies on the quantitative and qualitative characterization of glutathion proxidase. J Lab Med. 1987;70:158-65.

Qiang C, Du Y, Qin Y, Yu L, Zhou B, Feng W, et al. Overwintering physiology of the rice stem borer larvae, Chilo suppressalis Walker (Lepidoptera: Pyralidae): roles of glycerol, amino acids, low-molecular weight carbohydrates and antioxidant enzymes. Afr J Biotechnol. 2012;11:13030-9.

Sumida S, da Silva-Zacarin EC, Decio P, Malaspina O, Bueno FC, Bueno OC. Toxicological and histopathological effects of boric acid on Atta sexdens rubropilosa (Hymenoptera: Formicidae) workers. J Econ Entomol. 2010;103:676-90.

USDA report. Human Health and Ecological Risk Assessment for Borax (Sporax ) ${ }^{\circledR}$. FINALREPORT. Forest Health Protection USDA Forest Service. 2006.

Xue RD, Müller GC, Kline DL, Barnard DR. Effect of application rate and persistence of boric acid sugar baits applied to plants for control of Aedes albopictus. J Am Mosq Control Assoc. 2011;27:56-60. 